\title{
The impact of small group interaction on learners' grammatical accuracy achievement
}

\author{
Assia, Baghdadi $\square$ \\ University of M'sila, Algeria (assiabaghdadi1@live.fr) \\ Said, Keskes \\ University of Sétif, Algeria (keskaid@yahoo.fr)
}

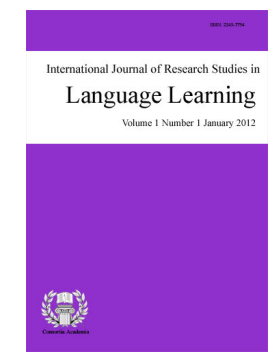

ISSN: 2243-7754 Online ISSN: 2243-7762

OPEN ACCESS DOI: $10.5861 /$ ijrsll.2013.511

\begin{abstract}
In an attempt to investigate the impact of small group interaction on EFL learners' grammatical accuracy achievement, methodological field experiments had been carried out with a sample of 30 students over a period of ten weeks of regular lectures in the Department of English, in one of the Algerian Universities. The obtained results indicated that learners' interaction and cooperation had a positive effect on EFL learners' achievement. And in order to scrutinise the existence and the frequency of the speech functions that might account for this effectiveness, a qualitative and a quantitative study had been conducted through the adoption of the Interaction Analysis Method. The results showed that within a cooperative learning context, factors such as the group size; the nature of the interaction; the learner's role within the small group, and the type of the task-based grammatical structure had an influential effect on EFL learners' grammar performance.
\end{abstract}

Keywords: grammar learning; interaction analysis; small group; group dynamics; task-based activity 


\section{The impact of small group interaction on learners' grammatical accuracy achievement}

\section{Introduction}

Thus far, much of research has focused on understanding classroom communication by looking at the interaction that occurs between teachers and students. However, another important dimension of classroom interaction has been ignored, that is, the interaction that occurs between the students themselves, and the impact that student-student interaction has on the patterns of communication, classroom learning, and opportunities for second language acquisition. But recently, and with the growing acceptance of communicative language learning and teaching techniques, a much greater interest has been attributed to the interactive group activities.

The background of this lies in Krashen's Input Theory in which he stated that learning takes place when the learner comprehends language at a level just beyond that of his current competency, and in the perspective of interaction he added that learners obtain "Optimal Input" through interaction, this input which is likely to lead to positive acquisition (Krashen, 1981). Swain (1985) shifted from comprehensible input to comprehensible output in which, according to him, L2 learners are forced to produce grammatical forms accurately, or at least with sufficient accuracy to be understood.

Vigotsky (1978) with his Sociocultural Theory argued that there is a strong relationship between interaction and cognitive development. The cognition develops as a result of social interaction. He proposed the (ZPD): Zone of Proximal Development in which there are two main stages of an individual's cognitive development. The first stage is what the learner can do by himself; the second one is what he can accomplish with the help of another. Moskowitz (1976) added that the communication of ideas is likely to foster learning through getting the learners more deeply involved in what they are doing.

In the same perspective, Johnson (1981) and associates were against much of research about classroom communication implied that real learning can occur only between teachers and students and that student-student interactions represent off-task behavior, discourage achievement, and lead to classroom disruptions. On the contrary, they argued, student-student interaction may actually be more important for educational success than teacher-student interaction. In fact, they claimed, constructive student-student interactions influence students' educational aspirations and achievement, develop social competencies, and encourage taking on the perspectives of others. Slavin (1980); Sharan (1980); Webb (1982) each provided in-depth reviews of research which overwhelmingly concluded that cooperative learning tasks in small groups enhance students' academic achievement, self-esteem, relationships among students of different ethnic backgrounds, and positive attitudes toward school.

Learners' interaction, cooperative learning, group work, small group activities are notions which are not considered considerably in the Algerian current educational system, especially in the EFL instruction which is still mostly whole-class, teacher-centered and large class enrolments. Learning a foreign language cannot be realized without grammar which is thought to furnish the basis for a set of language skills: listening, speaking, reading and writing. Grammar, in fact, gains its prominence in language teaching, particularly in English as a foreign language (EFL) and English as a second language (ESL), inasmuch as without a good knowledge of grammar, learners' language development will be severely constrained. Therefore, we aimed through this study to investigate the effect of small group interaction on the development of learners' accurate grammar performance in one of the Algerian universities. i.e., its role in enabling those learners to learn contextualized grammatical structures in a way that is far from the traditional way which is based on the memorization of a tedious set of rules, and the focus on correcting errors in a sentence. This traditional way in fact denies the learner involvement in the learning process, and considers the passive role of the learner who is mostly dominated by the teacher. 
The impact of small group interaction on learners' grammatical accuracy achievement

In this paper, the research study is based on the hypothesis claiming that small group interaction is likely to help learners of English grammar develop their grammatical accuracy, i. e., fostering the accurate and the appropriate use of learned grammatical structures in terms of form and meaning. The following research questions are going to be tackled:

a) Does the small group interaction help in fostering the learners' grammatical accuracy?

b) Are the developmental outcomes related to the nature of conversational interaction and to the extent of learner involvement?

\section{Literature review}

A large body of research explored the issue of conversational interaction and learner's comprehension, production and development. One of the interesting studies was the exploration of interaction and learner production by Gass and Varonis (1994). Although one aspect of their study of the effects of interaction on second language comprehension had been the topic of prior work, learner production was relatively underexplored. Gass and Varonis compared prescripted modified and unmodified input with and without the opportunity for interactional modifications on (a) comprehension, as measured by the performance of learners when receiving directions on tasks, and (b) production, as measured by their native speaker partner's success in following the directions. They found that both negotiated and modified input positively affected comprehension and that prior negotiated interaction but not prior modified interaction significantly affected production that was measured by the ability to give directions. Gass and Varonis suggested that interaction with the opportunity for modifications may affect later language use.

In two more studies published in 1994, more direct measures of production and acquisition were used. The findings were somewhat contradictory. Loschky (1994) considered the effects of comprehensible input and interaction on comprehension, the retention of vocabulary items or the acquisition of two locative constructions in Japanese as a second language (JSL). His study showed that negotiated interaction had a positive effect on the comprehension of the vocabulary but no effect on the retention or acquisition of the vocabulary items or the acquisition of grammatical structures. Ellis, Tanaka, and Yamazaki (1994), however, found that interactionally modified input resulted in both (a) better comprehension and (b) more new words being acquired than was the case with premodified input. Ellis et al.'s study was based on the ESL of two groups of Japanese L1 learners and provided evidence for a link between interactionally modified and lexical acquisition. They argued that an interaction gives learners control over the input and enables them to identify and solve problems.

In a study by Porter (1986), native speaker-learner and learner-learner interactions were compared to investigate the quality of input and interaction as well as the incidence of feedback. She found that native speakers corrected their own and the learners' errors more consistently. However, error correction was rare in both conditions. Native speakers corrected only eight per cent of learner errors. Error correction was rarely explicit in either condition. Additionally, native speakers did not miscorrect errors; learners' miscorrections, while rare, did occur in her data. Porter's findings suggest that learner-learner interactions may not provide sufficient opportunities for learners to receive feedback on their interlanguage output.

A qualitative study by Mackey (1999) aimed to identify whether learners developed in terms of question structures that they modified in their responses to implicit negative feedback. Her analysis examined the production of a small set of (a) learners who demonstrated a pattern of producing modified responses and (b) learners who demonstrated a pattern of not modifying any response. She found that learners who modified question forms in their responses increased their production of one type of higher-level question form. She concluded that having the opportunity to receive implicit negative feedback through signals of negotiation and then actually modifying output in response to such feedback may be a factor in the link between interaction and particular question forms, but only for some question forms. This finding seems to support the positions of (Sato 1986; Pica, 1994; Long, 1996) that interaction may be facilitative of some interlanguage forms and may not be 
as important or necessary in the development of others.

The importance of learners' collaborative attention to form in interaction has been investigated by many researchers who proved that learner-learner interactions provide a context for learners to receive feedback on the target likeness of their output (Doughty, 2001; Doughty \& Williams, 1998; Long \& Robinson, 1998). Though the optimal level of consciousness while processing input is debatable, it is claimed that corrective feedback gives learners an opportunity to make a cognitive comparison between their interlanguage and the given input (Ellis, Loewen, \& Erlam, 2006) and to engage in focused input analysis (Ellis, 2005). Williams' (2001) research, for instance, lends support to the effectiveness of classroom interaction for promoting the use of feedback strategies that can lead to formal learning. However, these data gain seem to indicate that learners benefit more from discussing form with a native speaker than with another learner. Although there were many research studies dealing with the effectiveness of corrective feedback in native speaker-learner interaction in promoting L2 development, there is still a need for further evidence of the learner-learner feedback effectiveness. In the current study we aimed at investigating this issue to confirm the utility and the benefit of the feedback that result from learner-learner interaction.

Research on negotiation for meaning indicated also that learners' communication breakdowns trigger negotiation for meaning (Gass, 2003; Pica, 1994). However, native speaker-learner and learner-learner interactions may differ with respect to both the quantity of negotiation sequences and the variation in negotiation moves. In terms of quantity of negotiation moves, learners tend to self-correct more while interacting with one another than when they interact with native speaker (Buckwalter, 2001; Sato \& Lyster, 2007; Shehadeh, 2001). And they also tend to engage in more such negotiations (Porter, 1986; Varonis \& Gass, 1985b) during which they use interactional moves claimed to benefit L2 development, such as input modifications (Garcia \& Pica, 2000) and interactional feedback (Adams, 2007; Gass \& Varonis, 1989; Soler, 2002).

In addition to differences in quantity of negotiation moves, native speaker-learner interactions may differ from learner-learner interactions in the types of negotiation moves used. While for native speakers, negotiation moves mainly involve repeating, simplifying, or expanding the input (Gass \& Varonis, 1984, 1985b; Varonis \& Gass, 1985a), for learners negotiation of meaning can also serve as attempts to make their speech more targetlike to be comprehensible for their interlocutor, either other learners or native speakers (Swain \& Lapkin, 1998, 2001, 2002; Silver, 2000; McDonough, 2005). While previous research indicated that negotiation for meaning may be quite frequent in learner-learner interactions, and may provide a restricted set of feedback types which may hinder learner developmental needs, there still remains little evidence of its effectiveness in promoting learning and of finding the possibility of expanding the feedback types scale. Through our study, we purposed to immerse learners within a context where they engage in task-based activities that trigger them to negotiate form and meaning using different communication strategies and different speech functions to complete the task at hand.

In summary, empirical research proved that the use of feedback in learner-learner interactions differs significantly from that in native speaker-learner interactions in ways that may be significant for language acquisition, and for grammar learning specifically such as negotiation for meaning, and opportunities to modify output following feedback which may occur more frequently in learner-learner interactions. Also, it indicated that learning facilitated by native speaker-learner interactions is not equivalent to learning facilitated by learner-learner interactions. Consequently it cannot be assumed that the demonstrated benefits of native speaker-learner interactions apply to learner-learner interactions as well. Therefore empirical evidence is strongly required to investigate whether grammar learning can be promoted by learner-learner interactions especially that this type of interaction makes the majority of interactions in classroom settings, and may be a significant source of feedback for learners. In our study, we did not aim only to detect the effect of the learners' interaction on grammar development as had been discussed in many previous research studies, but to go further through analysing the learners' interactions and pinpointing the different speech functions that were behind this effectiveness. 


\section{Methodology}

The whole research is based on two scientific methods: 1) the Experimental Method through which the cooperative small group interaction effect is investigated empirically using one independent variable that is learners' cooperative interaction, and one dependent variable that is the learners' grammatical accuracy development. And 2) the Interaction Analysis Method which studies the social organization of "conversation", or "Talk-in-interaction" by a detailed inspection of tape recordings and transcriptions made from such recordings. Its central goal is the description and explication of the competencies that ordinary speakers use and rely on in participating in intelligible, socially organized interaction (Paul, 1990).

\subsection{The Experimental Method}

\section{The participants}

The current empirical study was assigned to the population of first year students in the Department of Languages in an Algerian University. In selecting the required sample we applied the stratified random sampling through which the study population was firstly stratified into three strata according to the learners' achievement: high-proficiency level, the intermediate-proficiency level, and the low-proficiency level. In realizing this we referred to learners' achievement records. From each stratum ten (10) students were selected randomly. By the end we got a sample of (30) members which represented (10\%) of the whole population. Then we formed two groups: the experimental group, and the control group containing (15) members each, where the three level-based strata were represented by (5) members in each group.

\section{Design and procedure}

The empirical work took place during the first semester. It lasted ten (10) weeks. The tests were carried out weekly along with the content of the official curriculum which is divided into units where each unit is devoted to tackle one specific grammatical structure. In conducting the experiments, the tests were carried out using the Grammar Dictation Approach that is proposed by Wajnryb (1988). This approach is thought to be the most convenient approach since it is based on the idea of approaching grammar within context where language forms, structures, and patterns are treated from the perspective of their particular contextual meaning rather than as instances of rules where usage is devoid of a semantic base. The procedure of each test consisted of four stages:

The preparation stage - At this stage the teacher has to follow three steps: first, he prepares the learners for the text they will be hearing by exploring the warm-up suggestions in each lesson. Second, he prepares the learners for the vocabulary of the text. This vocabulary should be pre-taught if the teacher suspects that it is unknown to the learners or difficult for them to infer. Third, the teacher should ensure that the learners know what they are expected to do at each stage of the procedure. Fourth, the teacher should organize the learners into groups before the dictation begins.

The dictation stage - In this stage the teacher should read the short text that is constituted of five sentences. Each sentence contains the target grammatical structure. The text should be read three times at a slower pace than the teacher's natural speaking rate. The learners belonging to both groups are asked to take notes independently using their note-taking sheets.

The reconstruction stage - As soon as the dictation is finished, the experimental group members should interactively proceed to pool their notes and share them for five minutes to discuss the use of the introduced grammatical structure. However, the control group members should study their notes individually for five minutes being allowed to consult dictionaries and textbooks to supplement their notes. The learners are advised to pay special attention to the production of the target grammar forms. After the completion of the reconstruction phase the text reconstruction sheets should be collected for the analysis.

The analysis and correction stage - After the analysis and the scoring of the learners' reconstructed texts, a 
Assia, B. \& Said, K.

collective correction is set by the teacher with the members of both groups.

\section{Results}

The whole developmental stages of both groups' achievement during the whole empirical work are plotted in table (01) and illustrated in figure (01) below.

\section{Table 1}

The Results Obtained by the Experimental and the Control Groups During the Whole Empirical Work.

\begin{tabular}{|c|c|c|c|}
\hline \multirow[b]{2}{*}{ Weekly tests } & \multirow[b]{2}{*}{ The introduced grammatical structure } & \multicolumn{2}{|c|}{ Groups' achievements } \\
\hline & & $\begin{array}{l}\text { The experimental } \\
\text { group mean score }\end{array}$ & $\begin{array}{l}\text { The control group } \\
\text { mean score }\end{array}$ \\
\hline The first test & The simple present tense & 05 & 04 \\
\hline The second test & The auxiliary to be in the simple past tense & 6.44 & 5.66 \\
\hline The third test & $\begin{array}{l}\text { The simple past tense: regular and irregular } \\
\text { verbs }\end{array}$ & 5.32 & 3.77 \\
\hline The fourth test & $\begin{array}{l}\text { The simple past tense: the negative and the } \\
\text { interrogative forms }\end{array}$ & 6.53 & 5.66 \\
\hline The fifth test & $\begin{array}{l}\text { The comparative forms of short and long } \\
\text { adjectives }\end{array}$ & 5.23 & 3.20 \\
\hline The sixth test & $\begin{array}{l}\text { The future tense: } \\
\text { 1. The affirmative form. } \\
\text { 2. The negative form. } \\
\text { 3. The interrogative form. }\end{array}$ & 7.51 & 5.75 \\
\hline The seventh test & Must \& Must not & 7.06 & 4.75 \\
\hline The eighth test. & $\begin{array}{l}\text { The superlative forms of short and long } \\
\text { adjectives. }\end{array}$ & 7.82 & 5.10 \\
\hline The ninth test. & The simple past tense using the adverb ago. & 8.60 & 5.56 \\
\hline The tenth test. & The passive voice. & 8.75 & 6.77 \\
\hline
\end{tabular}

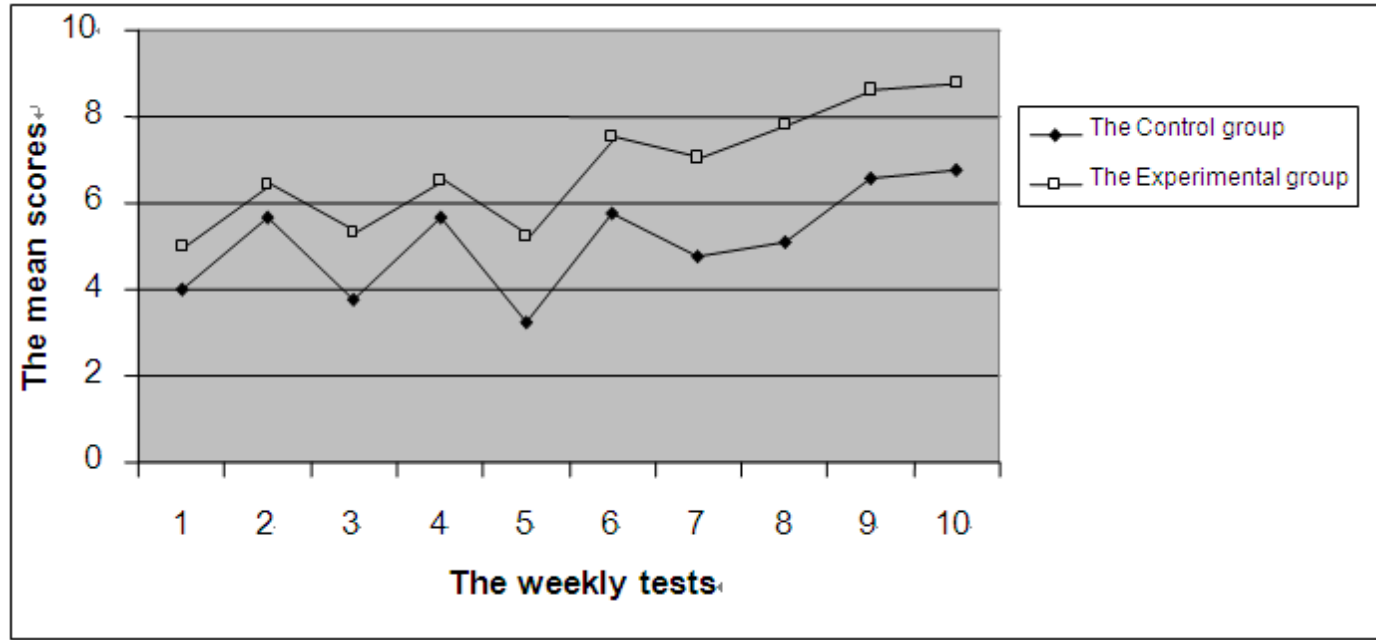

Figure 1. The Developmental stages of the whole empirical work

From the above figure, it can be clearly seen that the experimental group achievement outweighed the one of the control group. However, the simultaneity between the two groups' outcomes in terms of ups and downs is obvious. Accordingly, the aforementioned recapitulating graph can be divided into two phases. The first phase 
The impact of small group interaction on learners' grammatical accuracy achievement

lasted seven weeks where the instability of both groups' achievements was clearly obvious; the second one lasted the last three weeks where both groups' performances showed an increase. The detailed statistical description of both groups' results is stated in the following:

Test (01): in the first test we dealt with the simple present tense. The experimental group mean score reached (05) out of ten outweighing by that the control group whose mean score was (04).

Test (02): in the second test where the target grammatical structure was the use of the auxiliary 'To Be' in the simple past tense, figure (01) indicates the development of both groups' achievements. (6.44) was the mean score obtained by the experimental group, and (5.66) was the one reached by the control group.

Test (03): figure (01) reveals a noticeable regression attained by both groups whose target grammatical structure was about the simple past tense: the regular and the irregular verbs. The control group got (3.77) unlike the experimental group who got (5.32).

Test (04): the results obtained in this test shows the significant development achieved by both groups where the experimental mean score shifted to (6.53), whereas the control group progressed by reaching (5.66). They tackled the simple past tense: the negative and the interrogative forms.

Test (05): a careful observation of the above figure shows a surprising decrease of both groups who dealt with the comparative forms of short and long adjectives. The result achieved in this test can be regarded as a turning point for the whole developmental procedure because both groups got their lowest mean scores. (5.23) was the one of the experimental group, and (3.20) was the one of the control group.

Test (06): a significant development of both groups is obvious. (7.51) was the mean score attained by the experimental group, (5.75) was the one achieved by the control group. The grammatical structure was the future tense.

Test (07): in the seventh test a significant difference between the two groups' results was noticed where (4.75) was the mean score reached by the control group. The experimental group, in contrast, although its mean score lowered to reach (7.06) but this decrease was not significant compared to its previous achievement.

Tests (08), (09) \& (10): the results obtained in the last three tests show the remarkable development of both groups. In the eighth test the target grammatical structure was the superlative forms of short and long adjectives. (7.82) was the experimental group mean score, (5.10) was the one of the control group. In the ninth test, (8.60) and (6.56) were the experimental and the control group results respectively. The grammatical structure was the simple past tense using the adverb ago. In the tenth test, (8.75) was the highest mean score reached by the experimental group. (6.77) was the one reached by the control group. They dealt with the passive form.

\section{Discussion}

The shift from teacher-centred classroom to learner-centred has induced learners to become more responsible for their own learning and it led learners to a kind of effort for becoming more autonomous (Rubin, 1987). Therefore, learners are no longer considered as sponges but they can rely on their own thinking and apply different roles and different mental strategies in order to tackle their learning problems. The major finding of this study was that cooperative learning-based grammar instruction did affect positively the learners' development of structural knowledge, although many facts had been revealed through the analysis of the learners' outcomes.

The unsatisfactory results achieved by the learners during the first stages can be interpreted by their tendency to the individual work rather than to the collaborative one. On the other hand, it may be referred to the effect of some personality traits such as: introversion, shyness, and the lack of self-confidence. But through time, the learners' results started to advance as they got accustomed to the experimental procedure, and also to the interactive context they were involved in where a dynamic interaction was noticed. In this perspective, Gass and 
Assia, B. \& Said, K.

Varonis (1994) claimed that the absence of short term effects does not exclude the possibility of long term effects when the learner has had sufficient time to process and incorporate the feedback.

This phenomenon can be also explained, according to TUCKMAN's Small Group Development Theory, by the fact of overriding the forming stage that was dominant during the first interactions where the group members were more concerned with setting their interpersonal relationships by learning about each other and the task at hand. In the following experimental tests, by contrast, they moved directly to the forthcoming stages such as the storming where the group members became more comfortable with each other and they engaged each other in arguments and vied for status in the group. And then to the norming stage in which the learners assigned their goal and they addressed the different types of communication that would or would not help in the task. In the performing stage, the group members reached a conclusion. The final is adjourning where the group members projected ends and disbanded (Borchers, 2010).

The type of the role played by the learner during the interaction proved its influential impact on the group performance. For instance, in one of the interactions the interpersonal relationships were characterized prominently by the emergence of conflicts among the interactor learners, which frustrated remarkably the ongoing of the group dynamics. In another one, some of the learners adopted roles such as the dominator role, the blocker role or the aggressor one. Such roles are considered by Borchers as group destructive ones.

As far as the introduced input is concerned, two possible explanations may be stated. The first one is related to the input susceptibility to interaction. In this paradigm, it is interesting to note that the learners performed better in dialogues than in the descriptive or narrative texts, and that was due to the existing approximation between the introduced dialogues and their real-life interactional setting. The second explanation may be attributed to the extent of the complexity of the introduced grammatical structure. In the interest of exploring the nature of the interaction by determining its features or characteristics, we found it necessary to adopt the Interaction Analysis Method. The latter may be conceived as a specific analytic trajectory that may be used to reach a specific kind of systematic insight in the ways learners do interaction.

\subsection{The Interaction Analysis Method}

\section{The participants}

To scrutinize the link between the nature of the interaction and the size of the group involved in it, the interactor group was divided into three size-based groups: the first group consisted of five learners, the second group consisted of ten learners, and the third one contained fifteen learners.

\section{The investigation tool}

In gathering the data, the three groups' interactions were recorded using the videotape, which is thought to be the most convenient tool to provide the researcher with the required detailed data that can't be obtained through direct observation.

\section{Data collection procedure}

Firstly, the participants were divided into three subgroups. Each subgroup interaction was recorded separately. The recording was limited to the reconstruction phase while the small group members were sharing their notes and discussing the production of their own versions. The duration of each recording was five minutes.

\section{Data analysis instruments}

Despite the abundance of interaction analysis instruments, it was difficult to decide upon a system that is practical, not cumbersome and more convenient to the assigned objectives. Finally, one fairly simple system in this tradition was selected: Brown Interaction Analysis System (BIAS), which is a descriptive framework that aims to analyse classroom verbal interaction (Brown \& Wragg, 1993). 
The impact of small group interaction on learners' grammatical accuracy achievement

For the sake of making it more relevant to the small group interaction context, several adaptations, extensions and simplifications were proceeded on it. The basic descriptive categories in the adapted BIAS were ten speech functions: questioning language use, repairing grammatical forms, asking for explanation, explaining, confirming, proposing, agreeing, disagreeing and silence.

\section{Data coding and quantification}

In implementing the (BIAS), a time-line display sheet was used and marked every three seconds along the duration of the observation. Once a whole small group interaction had been coded, percentages were calculated for each of the speech functions noted, to be then presented in a histogram, analysed and interpreted. For purposes of analysis each small conversation was divided into transactions, exchanges and moves. A transaction is defined as one or more exchanges on the same topic, usually a clause or a phrase from the text at hand or about it. An exchange consists minimally of two moves, an initiation or opening and a response (Sinclair \& Coulthard, 1975).

\section{Results}

The descriptive statistics of the rates of frequency of the different speech functions existing in the interactions of the three groups are presented in the following:

Five learners group interaction - Table (02) and figure (02) summarize the frequencies of the speech functions that existed in the interaction of five pupils. They show that repairing grammar forms outweighs all the speech functions by getting $(29.35 \%)$. (14.67\%) was the frequency attained by the speech function of proposing. Asking for explanation, and explaining gained respectively $(7.33 \%)$ and $(8.25 \%)$. The speech function of questioning language use received $(9.17 \%)$. Agreeing, disagreeing and confirming were also present in the interaction where they got respectively $(5.50 \%),(11.92 \%)$ and $(10.09 \%)$. Silence was represented by $(3.66 \%)$.

Table 2

The Frequency of the Speech Functions Found in the Tape of Five Learners Group Interaction

\begin{tabular}{cccccccccc}
\hline $\begin{array}{c}\text { Speech } \\
\text { function }\end{array}$ & $\begin{array}{c}\text { Questioning } \\
\text { language } \\
\text { use }\end{array}$ & $\begin{array}{c}\text { Repairing } \\
\text { grammar } \\
\text { forms }\end{array}$ & $\begin{array}{c}\text { Asking for } \\
\text { explanation }\end{array}$ & Explaining & Confirming & Agreeing & Disagreeing & Proposing & Silence \\
\hline $\begin{array}{c}\text { Rate of } \\
\text { frequency } \\
\text { in ten } \\
\text { learners } \\
\text { group }\end{array}$ & $9.17 \%$ & $29.35 \%$ & $7.33 \%$ & $8.25 \%$ & $10.09 \%$ & $5.50 \%$ & $11.92 \%$ & $14.67 \%$ & $3.66 \%$ \\
\hline
\end{tabular}

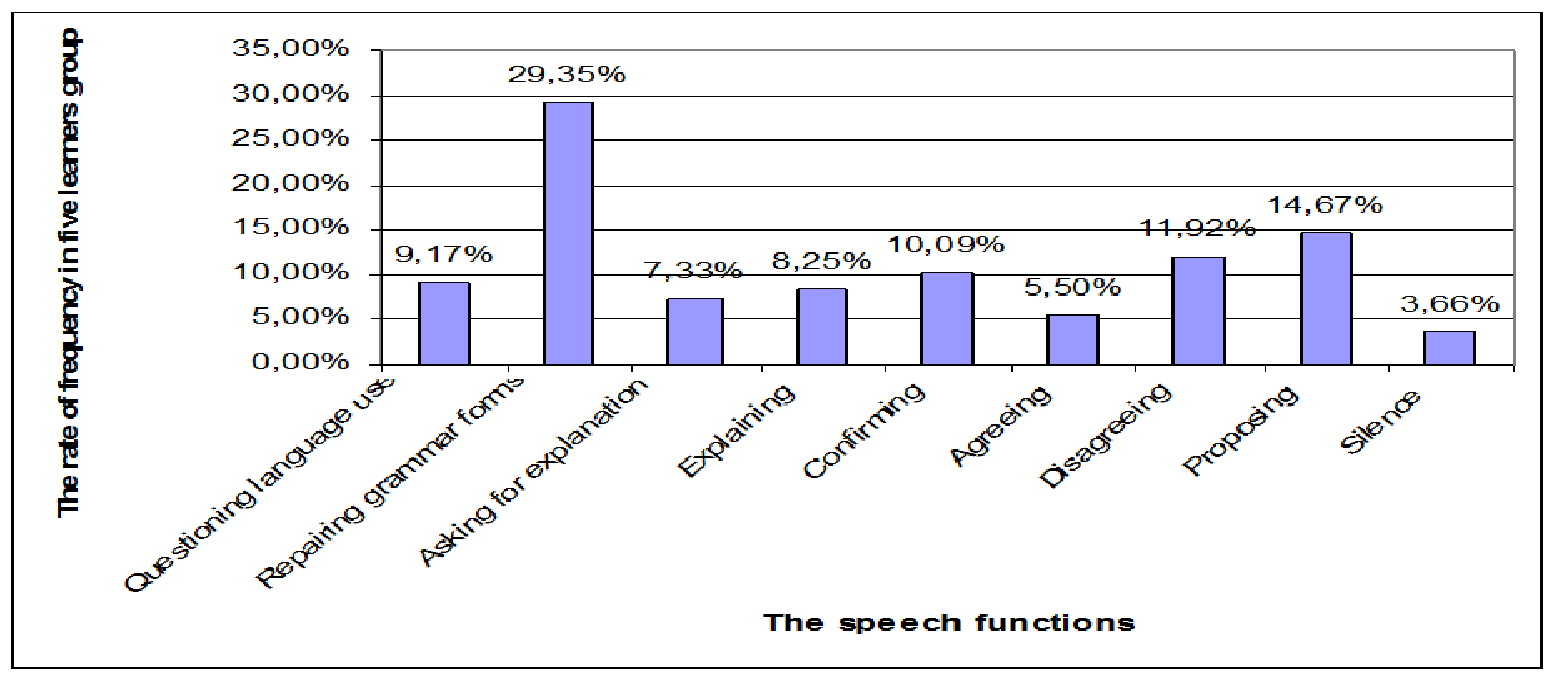

Figure 2. The frequency of the speech functions found in the tape of five learners group 
Assia, B. \& Said, K.

Ten learners' group interaction - From the illustrating table (03) and figure (03), repairing grammatical forms speech function gained the highest percentage (37.28\%). Questioning language use and asking for explanation received the percentage $(8.47 \%)$ which is low compared to that of the explaining speech function which reached $(15.25 \%)$. The confirming speech function got (13.55\%). (6.77\%), (5.08\%), and (5.08\%) represented respectively the proposing, the agreeing, and the disagreeing. The silence speech function did not exist in this interaction.

Table 3

The Frequency of the Speech Functions Found in the Tape of Ten Learners Group Interaction

\begin{tabular}{|c|c|c|c|c|c|c|c|c|c|}
\hline $\begin{array}{l}\text { Speech } \\
\text { functions }\end{array}$ & $\begin{array}{c}\text { Questioning } \\
\text { language } \\
\text { use }\end{array}$ & $\begin{array}{c}\text { Repairing } \\
\text { grammar } \\
\text { forms }\end{array}$ & $\begin{array}{l}\text { Asking for } \\
\text { explanation }\end{array}$ & Explaining & Confirming & Agreeing & Disagreeing & Proposing & Silence \\
\hline $\begin{array}{c}\text { Rate of } \\
\text { frequency } \\
\text { in ten } \\
\text { learners } \\
\text { group }\end{array}$ & $8.47 \%$ & $37.28 \%$ & $8.47 \%$ & $15.25 \%$ & $13.55 \%$ & $5.08 \%$ & $5.08 \%$ & $6.77 \%$ & $0 \%$ \\
\hline
\end{tabular}

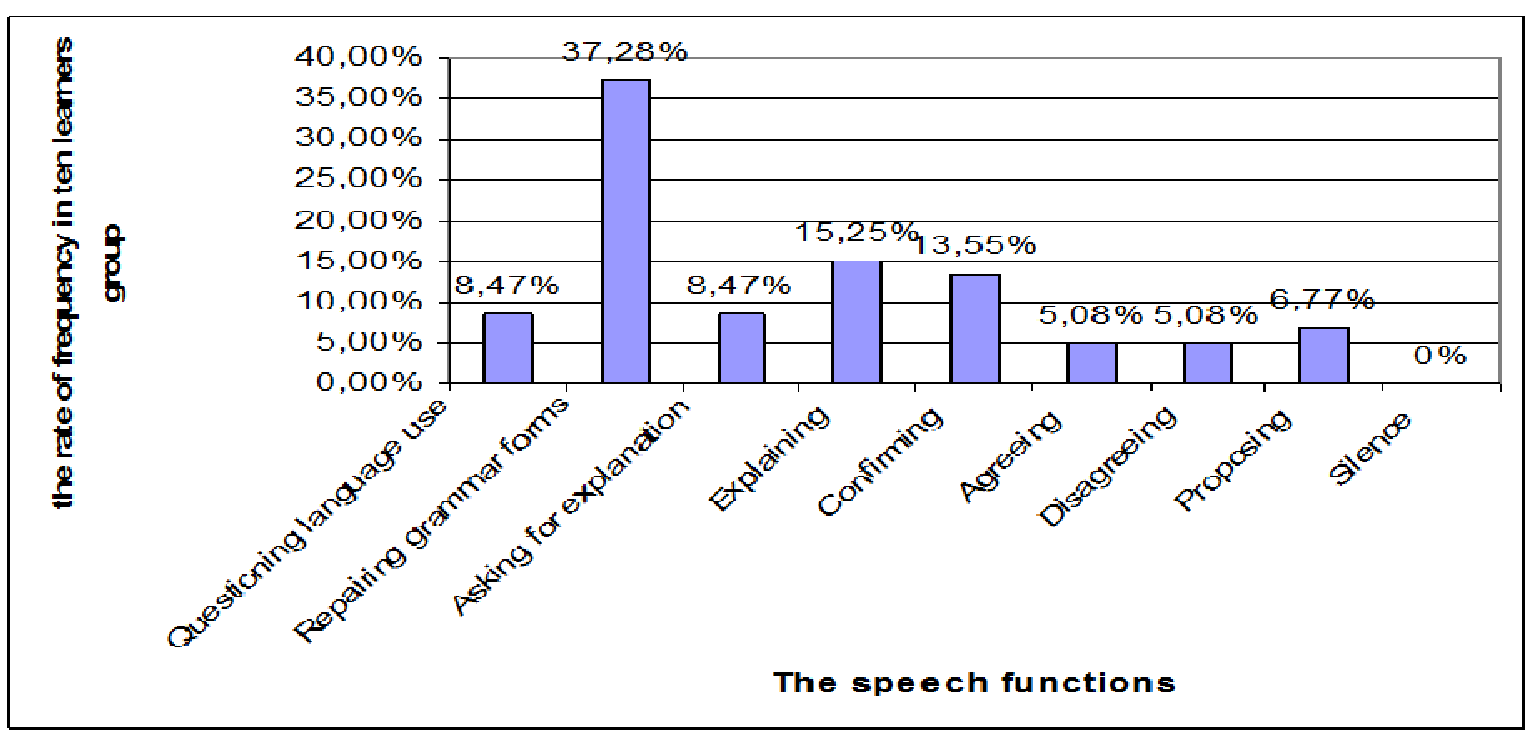

Figure 3. The frequency of the speech functions found in the tape of ten learners group

Fifteen learners group interaction - The occurrence of the speech functions illustrated in table (04) and figure (04) indicates that repairing grammar forms gained (20\%). Questioning language use received (10\%). Asking for explanation and explaining got respectively (14\%), and (10\%). The disagreeing speech function received $(22 \%)$ unlike the proposing speech function which got $(4 \%)$. $(8 \%)$ was the rate of occurrence gained by the proposing and the confirming speech functions. As far as the silence speech function is concerned, no sign of its existence.

\section{Table 4}

The Frequency of the Speech Functions Found in the Tape of Fifteen Learners Group Interaction

\begin{tabular}{cccccccc}
\hline $\begin{array}{c}\text { Speech } \\
\text { functions }\end{array}$ & $\begin{array}{c}\text { Questioning } \\
\text { language use }\end{array}$ & $\begin{array}{c}\text { Repairing } \\
\text { grammar } \\
\text { forms }\end{array}$ & $\begin{array}{c}\text { Asking for } \\
\text { explanation }\end{array}$ & Explaining & Confirming & Agreeing & Disagreeing \\
\hline $\begin{array}{c}\text { Rate of } \\
\text { frequency } \\
\text { in ten } \\
\text { learners } \\
\text { group }\end{array}$ & $10 \%$ & $20 \%$ & $14 \%$ & $10 \%$ & $8 \%$ & $4 \%$ & $22 \%$ \\
\hline
\end{tabular}


The impact of small group interaction on learners' grammatical accuracy achievement

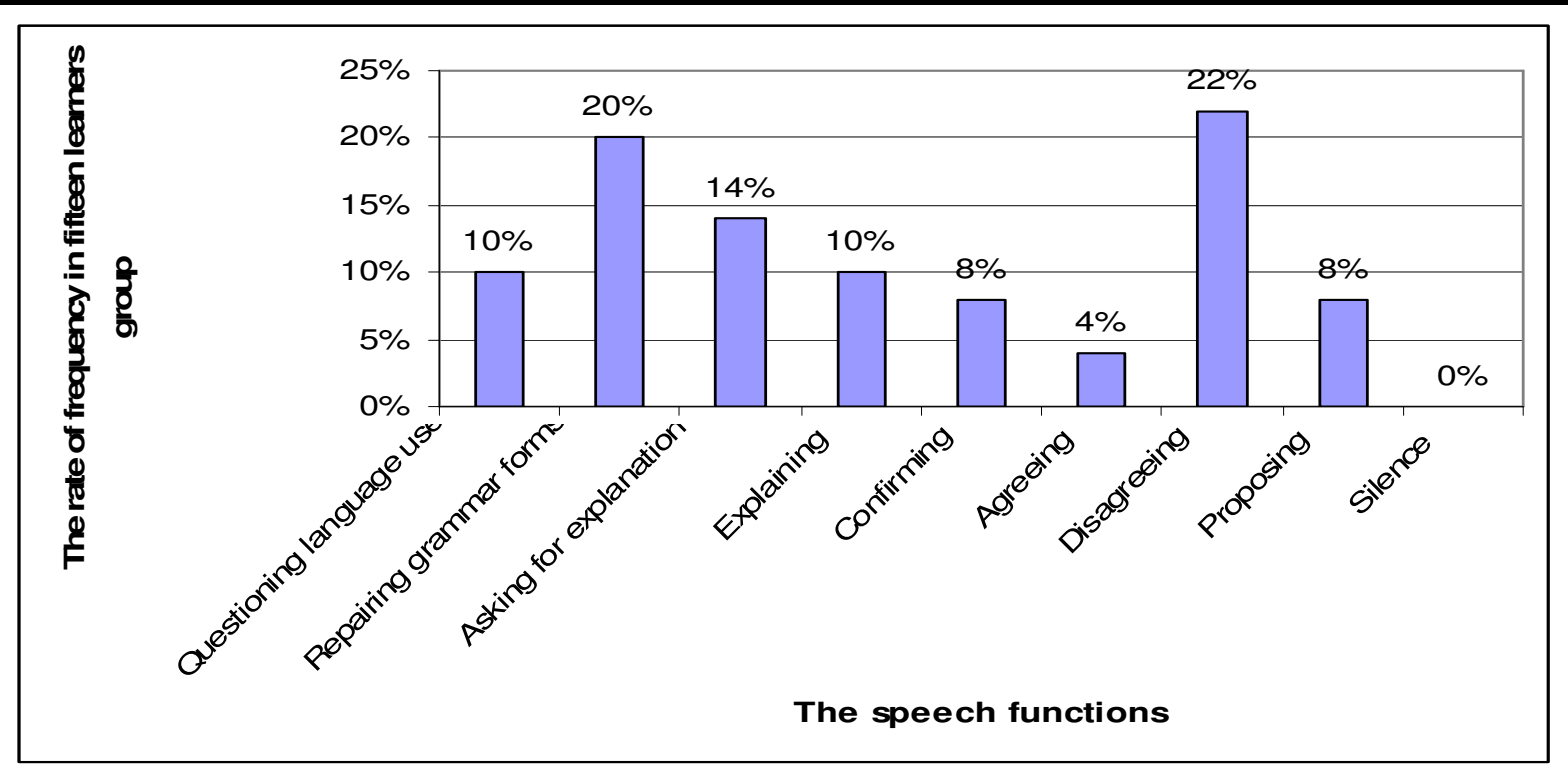

Figure 4. The frequency of the speech functions found in the tape of fifteen learners group

\section{Discussion}

In the aim of detecting the effect of the group size on the nature of the interaction, a comparison was purposefully preceded between the three groups interactions after analysing each group's interaction qualitatively and quantitatively. In carrying out this comparison we based ourselves on a careful observation of the tapes to get a detailed picture about the ongoing of the group dynamics; and also to interpret the differences existing between the rates of occurrence of each speech function in each group.

As a matter of fact, we found that the larger the group the fewer members have the chance to participate. Thus, it becomes more likely that reticent members fail to contribute though they might well enjoy the relative anonymity a large group affords them. On the other hand, we noticed that the smaller the group the greater the likelihood of close relationships, full participation, and consonance of aims. Moreover, we found that the smaller the group the more responsibility for the text at hand is born by each member of the group, and the more the group work is organized.

As far as the speech functions are concerned, the smaller the group the greater the possibility of questioning language use. Because it was apparent that factors like the learning anxiety, the anonymity, the fear of being laughed at, the reliance upon the other peers were likely to emerge in larger groups. The repairing of grammar forms got the lowest rate of frequency in the group of fifteen learners unlike in the other two groups, where its rates of occurrence were considerable. This fact indicates that the context where the group size ranges from five to ten learners provides the learners with the opportunity of noticing the gap in their knowledge by diagnosing their weaknesses and strengths. Moreover, it contributes to the raising of the learners' consciousness of the language patterns and structures.

The rates of frequency of asking for explanation and the explaining speech functions were remarkably approximate in the smallest group unlike in the other two groups where the difference between the two speech functions' frequencies was considerable. Such fact confirms that the smaller the group, the more peaceful the group context is, and the greater coherence is between the two speech functions and the regularity in turn-taking distribution.

The proposing speech function was highly practiced by the group of five learners who found this context encouraging for proposing, persuading, arguing, and also for realizing greater responsibility for the group work.

In the perspective of agreement and disagreement, we noticed that the agreement speech function frequency 
rates were approximate in the three groups. The disagreement, by contrast, existed considerably in the largest group. This result indicates how much affective and peaceful the group context is when its structure is limited. In addition, it shows one important fact that is the kind of disagreement existing in each group. In this realm, it is worthy to mention that the disagreement may result in frequently and regularly conflicts among the interactors. Those conflicts are divided into two types: controversy and conflicts of interests (Johnson \& Johnson, 2003). Both types are inevitable results of the committed participation of members of cooperative learning groups.

Controversy exists when group members tend to reach agreement but they have different information, perceptions, opinions, reasoning processes, theories, and conclusions. Conflicts of interests, on the other hand, occur when the actions of one person striving to achieve his goal interfere with and obstruct the actions of another person seeking the same thing (Johnson \& Johnson, 2003). Controversies dominated noticeably in the smallest group, however; in the largest group conflicts of interests did. This fact shows that the emergence and the adoption of the aggressor role by the group members are likely to destroy the group dynamics and the group achievement as well.

Concerning the confirming speech function, the obtained results show that it got the lowest rate of occurrence in the group of ten learners. This ensures the fact that the possibility of confirming and ascertaining answers is greater in the smallest group. Hence, personality traits such as self confidence, the spirit of responsibility, and motivation are likely to be enhanced. Silence as a speech function did not exist neither in the group of ten learners nor in the one of fifteen learners, but it was practiced remarkably in the group of five learners. Pedagogically speaking, we can say that within a restricted group learners can be provided with a convenient context that can foster their concentration, their deep thinking, their rigor in decision making and consequently their group achievement.

Irrespective of the group size, it is worthwhile to mention that during the reconstruction phase the learners pooled their knowledge of grammar, lexis and discourse in the creation of their own versions. The fact that learners discussed linguistic problems and decisions contributed to activate the explicit linguistic knowledge and might even raise the implicit linguistic knowledge to consciousness. Learners were put in a position of having to voice their linguistic hypotheses. Being voiced, these hypotheses become clearer and more conscious to the learner.

The immersion of learners with disabilities in such small learning community was beneficial for the learner sitting over by the window, for the over-aggressive learner who seeks acceptance through negative behaviours, for the bright but stereotyped learner sitting in the front row, and also for the average learner in the centre of the classroom who needs very little help and is often neglected. Hence, all learners can be accepted and benefit from such interactive context where it is acceptable to be different. We have also found in this research that the cooperation between the different types of learners on instructional tasks leads to empathy, altruism, and to the ability of viewing situations from a variety of perspectives.

Finally, the failure of some topics to occur appropriately in one group or in another indicates that it may be difficult to predict topics that will occur with absolute certainty. And that the linguistic topics to be discussed will of necessity depend on the interest and knowledge of the group members, on the group size, and possibly on the general level of the group as well as its interpersonal group dynamics.

\subsection{Limitations}

It is important to recognize that the learners' sample in this study was quite small and that the learners were native speakers of Arabic and used French as L2. For that reason it was unclear to what extent these findings on the effectiveness of learner-learner interactional feedback apply to learners from other backgrounds in other learning contexts. For that reason, further research is needed to investigate the effectiveness of learners' interactions in other contexts. 
The impact of small group interaction on learners' grammatical accuracy achievement

The selection of the required sample was a crucial issue because individual differences are important criteria which need to be considered carefully especially that the sources of learning are complex and can be seen as stemming from learner-internal factors. In the current study, we focused mainly on learner's grammar proficiency. Factors such as age and background were to a considerable extent controlled unlike gender differences factor which was not emphasized because gender influence on L2 interaction and how males and females interact and collaborate to achieve a task need to be investigated in a separate and detailed research.

As far as the interactive context is concerned, we noticed through the observation of the tapes that many grammatical forms emerged naturally wrongly and it was not possible to determine whether the learners did not know the correct linguistic forms before the interactions. It is possible that some forms were known and the errors made stemmed not from the interlanguage representations, but rather from the communicative pressure of completing an interactive task with another learner and should be considered mistakes rather than true errors. It is indeed rarely possible regardless of the type of linguistic data to determine precisely what learners actually do and do not know. Therefore, the obtained results should be interpreted with caution, and should be sustained with other research methods such as the descriptive method or the introspective one.

\section{Conclusion}

This study provided direct empirical support for the claim of the interaction hypothesis: small group interaction did contribute to the development of learners' accurate grammar performance. Clearly, the nature of the interaction and the role of the learner with the type of the introduced structures proved to be important factors that may affect and may be affected through interaction.

This study attempted to identify the types of interaction that learners used while engaging in a cooperative task; and also to reveal the effect of the group size on the interaction ongoing. The Interaction Analysis Method allowed witnessing how the interactor learners approached language learning by using different speech functions such as; questioning language use, repairing grammar forms, asking for explanation, explaining, confirming, agreeing, disagreeing and silence. As well as the code-switching that had been highlighted in the current research. Moreover, it revealed one crucial issue that is the smaller the group, the more successful, effective and efficient is the interaction.

The clustering effect of small group interaction on the development of learners' grammatical accuracy took place over time. This effect resulted from two major issues. The first one is the introduced grammar approach that is based on three main principles: a) learners should attend both meaning and form when learning grammar; b) new grammatical features are more likely to be acquired when learners notice and comprehend them in input; and c) learners' awareness of grammatical forms helps them to acquire grammatical features slowly and gradually more than when they engage in extensive production practice. The second issue has to do with the advantages of small group work over whole-class instruction. Among them: raising the learners' consciousness of specific aspects of language in texts; encouraging the learners to learn from each other by pooling their knowledge; and also enabling them to find out what they do or do not know about English.

Additionally, it provides a greater quantity of learner practice opportunities, a more individualized pace of instruction, increased personal investment leading to higher motivation, and a positive affective climate, which reduces stress and enhances linguistic risk-taking if factors such as stress, anxiety, and conflicts are wisely managed by the teacher. Moreover, small group activities may cause learners' communicative competence to improve in terms of both fluency and communication strategies. And because small group verbal interaction resembles closely a naturally occurring face-to-face interaction outside the classroom, it is assumed to provide the learners with social skills like leadership, decision-making, conflict management, conversation management and use of a wide range of language functions that are likely to be acquired by the learners engaged in small group interactive context. 


\subsection{Implications and suggestion for future research}

The finding that L2 learners interactions in small groups is effective and feasible is encouraging especially for foreign language settings in which students do not have much chance to either interact in the target language or benefit from the effects of corrective feedback provided in that small learning and interactive context. Moreover, the class is usually too large for learners to engage in communication and receive feedback from their peers, so peer interaction creates an ideal context for transfer-appropriate processing mainly that interaction between nonnative speakers is becoming a more likely real-life situation that learners will encounter. Giving L2 learners opportunities to engage in negotiation of form can also be recommended because it proved its effectiveness in accuracy development. Additionally, it is important to note, however, that the learners in the present study were already form oriented and needed to proceduralize their rule-based knowledge to access it during spontaneous production. In such cases, it may not be a good pedagogical option to have them become too analytical during meaningful interaction. Instead, it seems more important to give learners activities in which they engage in meaningful practice.

Through this research we did not want to suggest that there is no place for teacher discourse control, and no one dares deny the role of the teacher in the teaching/learning process. But implications arising from this study suggest that teachers, syllabus designers and material developers should take into account several important principles of language learning such as learner autonomy, learner involvement, cooperation and interaction among learners, focus on form and meaning, self and peer-assessment and this is through including interactive activities that provide students with a sense of achievement and personal accountability and encourage them to think about the process of language learning and how to approach it more effectively.

The results reached in this study are hoped to raise researchers' attention to the need of further and well detailed researches to investigate how exactly the small group interaction affects the learner's cognitive skills in grammar learning.

\section{References}

Adams, R. (2007). Do second language learners benefit from interacting with each other? In A. Mackey (Ed.), Conversational interaction in second language acquisition: A collection of empirical studies (pp. 29 51). Oxford: Oxford University Press.

Borchers, T. (2010). Small group communication: Roles in groups. Retrieved July 23, 2010, from http:www.abacon.com/commstudies/groups/roles.html

Brown, G., \& Wragg, E. C. (1993). Questioning. London: Routledge.

Buckwalter, P. (2001). Repair sequences in Spanish L2 dyadic discourse: A descriptive study. Modern Language Journal, 85, 380 - 397. http://dx.doi.org/10.1111/0026-7902.00115

Doughty, C. (2001). The cognitive underpinnings of focus on form. In P. Robinson (Ed.), Cognition and Second Language Instruction. Cambridge: Cambridge University Press. http://dx.doi.org/10.1017/CBO9781139524780.010

Doughty, C., \& Williams, J. (Eds.). (1998). Focus on form in classroom second language acquisition. New York: Cambridge University Press.

Ellis, N. C. (2005). At the interface: Dynamic interactions of explicit and implicit language knowledge. Studies in Second Language Acquisition, 27(2), 305-352. http://dx.doi.org/10.1017/S027226310505014X

Ellis, R., Loewen, S., \& Erlam, R. (2006). Implicit and explicit corrective feedback and the acquisition of L2 grammar. Studies in Second Language Acquisition, 28, 339-368. http://dx.doi.org/10.1017/S0272263106060141

Ellis, R., Tanaka, Y., \& Yamazaki, A. (1994). Classroom interaction, comprehension and the acquisition of L2 word meaning. Language Learning, 44(3), 449-491. http://dx.doi.org/10.1111/j.1467-1770.1994.tb01114.x

Garcia-Mayo, M. P., \& Pica, T. (2000). L2 learner interaction in a foreign language setting: are learning needs 
The impact of small group interaction on learners' grammatical accuracy achievement

addressed? International Review of Applied Linguistics, 38(1), 35-58.

Gass, S. M., \& Varonis, E. (1984). The effect of familiarity on the comprehensibility of nonnative speech. Language Learning, 34(1), 65-89. http://dx.doi.org/10.1111/j.1467-1770.1984.tb00996.x

Gass, S. M., \& Varonis, E. (1985b). Variation in native speaker speech modification to nonnative speakers. Studies in Second Language Acquisition, 7(1), 37-58. http://dx.doi.org/10.1017/S0272263100005143

Gass, S. M., \& Varonis, E. (1989). Incorporated repairs in nonnative discourse. In M. Eisenstein (Ed.),The Dynamic Interlanguage. New York: Plenum Press. http://dx.doi.org/10.1007/978-1-4899-0900-8_5

Gass, S. M., \& Varonis, E. (1994). Input, interaction, and second language production. Studies in Second Language Acquisition, 16, 283-302. http://dx.doi.org/10.1017/S0272263100013097

Gass, S. M. (2003). Input and interaction. In C. Doughty \& M. H. Long (Eds.), The Handbook of Second Language Acquisition (pp. 382-408). Oxford: Blackwell. http://dx.doi.org/10.1002/9780470756492.ch9

Johnson, D. W., \& Johnson, F. P. (2003). Joining together: Group theory and groupskills (8th ed.). Needham Heights, MA: Allyn and Bacon.

Johnson, D. W., Maruyama, G., Johnson, R., Nelson, D., \& Skon, L. (1981). Effects of cooperative, competitive, and individualistic goal structures on achievement: A meta-analysis. Psychological Bulletin, 89(1), 47-62. http://dx.doi.org/10.1037/0033-2909.89.1.47

Krashen, S. (1981). Second language acquisition and second language learning. Pergamon Press Inc.

Long, M. H., \& Robinson, P. (1998). Focus on form: Theory, research and practice. In C. Doughty \& J. Williams (Eds.), Focus on Form in Classroom Second language acquisition. Cambridge: Cambridge University Press.

Long, M. H. (1996). The role of the linguistic environment in second language acquisition. In W. C. Ritchie \& T. K. Bhatia (Eds.), Handbook of Second Language Acquisition. New York: Academic Press.

Loschky, L. (1994). Comprehensible output and second language acquisition: What is the relationship? Studies in Second Language Acquisition, 16(3), 303-325. http://dx.doi.org/10.1017/S0272263100013103

Mackey, A. (1999). Input, interaction, and second language development: An empirical study of question formation in ESL. Studies in Second Language Acquisition, 21(4), 557-587. http://dx.doi.org/10.1017/S0272263199004027

McDonough, K. (2005). Identifying the impact of negative feedback and learners' response on ESL question development. Studies in Second Language Acquisition, 27(1), 79-103. http://dx.doi.org/10.1017/S0272263105050047

Moskowitz, G. (1976). The classroom interaction of outstanding foreign language teachers. Foreign Language Annals, 135-143. http://dx.doi.org/10.1111/j.1944-9720.1976.tb02639.x

PAUL, T. H. (1990). Methodological issues in conversation analysis. Bulletin de Méthodologie Sociologique, 27, 23-51. http://dx.doi.org/10.1177/075910639002700102

Pica, T. (1994a). Research on negotiation: What does it reveal about second-language learning conditions, processes, and outcomes? Language Learning, 44(3), 493-527. http://dx.doi.org/10.1111/j.1467-1770.1994.tb01115.x

Porter, P. (1986). How learners talk to each other: Input and interaction in task-centered discussions. In R. Day (Ed.), Talking to Learn: Conversation in Second Language Acquisition. Rowley, Mass: Newbury House.

Rubin, J. (1987). Learner strategies: Theoretical assumptions, research history and typology. A. Wenden \& J. Rubin(Eds), New York: Prentice Hall.

Sato, C. (1986). Conversation and interlanguage development: Rethinking the connection. In R. Day (Ed.), Talking to Learn: Conversation in Second Language Acquisition. Rowley, Mass: Newbury House.

Sato, M., \& Lyster, R. (2007). Modified output of Japanese EFL learners: Variable effects of interlocutor vs. feedback types. In A. Mackey (Ed.), Conversational interaction in second language acquisition: A collection of empirical studies (pp. 123 - 142). Oxford: Oxford University Press.

Sharan, S. (1980). Cooperative learning in small groups: Recent methods and effects on achievement, attitudes, and ethnic relations. Review of Educational Research, 241-271. http://dx.doi.org/10.3102/00346543050002241 
Assia, B. \& Said, K.

Shehadeh, A. (2001). Self-and other-initiated modified output during task-based interaction. TESOL Quarterly, 35, 433-457. http://dx.doi.org/10.2307/3588030

Silver, R. E. (2000). Input, output, and negotiation: Conditions for second language development. In B. Swierzbin, F. Morris, M. E. Anderson, C. A. Klee, \& E. Tarone (Eds.), Social and Cognitive Factors in Second Language Acquisition: Selected Proceedings of the 1999 Second Language Research Forum. Somerville, Mass: Cascadilla Press.

Sinclair, J. M., \& Coulthard, M. (1975). Towards an analysis of discourse: The English used by teachers. Oxford: Oxford University Press.

Slavin, R. E. (1980). Cooperative learning. Review of Educational Research, 15- 42.

Soler, E. A. (2002). Relationship between teacher-led versus learners' interaction and the development of pragmatics in the EFL classroom. International Journal of Educational Research, 37, 359-377. http://dx.doi.org/10.1016/S0883-0355(03)00010-7

Swain, M. (1985). Communicative competence: Some roles of comprehensible input and comprehensible output in its development. In S. M. Gass \& C. Madden (Eds.), Input in Second Language Acquisition. Rowley, Mass: Newbury House.

Swain, M., \& Lapkin, S. (1998). Interaction and second language learning: Two adolescent French immersion students working together. The Modern Language Journal, 82(3), 320-337. http://dx.doi.org/10.1111/j.1540-4781.1998.tb01209.x

Swain, M., \& Lapkin, S. (2001). Focus on form through collaborative dialogue: Exploring task effects. In M. Bygate, P. Skehan, \& M. Swain (Eds.), Researching Pedagogic Tasks: Second Language Learning, Teaching, and Testing. London: Longman.

Swain, M., \& Lapkin, S. (2002). Talking it through: two French immersion learners' response to reformulation. International Journal of Educational Research, 37(3), 285-304. http://dx.doi.org/10.1016/S0883-0355(03)00006-5

Varonis, E. \& Gass, S. M. (1985a). Miscommunication in native/non-native conversation. Language in Society, 14(3), 327-343. http://dx.doi.org/10.1017/S0047404500011295

Varonis, E. \& Gass, S. M. (1985b). Non-native/non-native conversations: A model for negotiation of meaning. Applied Linguistics, 6(1), 71-90. http://dx.doi.org/10.1093/applin/6.1.71

Vygotsky, L. (1978). Mind in society. Cambridge, Mass: MIT Press.

Wajnryb, R. (1988). The theoretical bases of the dictogloss procedure of language teaching. A TESOL Occasional Paper, 5.

Webb, N. M. (1982). Student interaction and learning in small groups. Review of Educational Research, 52(3), 421-445. http://dx.doi.org/10.3102/00346543052003421

Williams, J. (2001). The effectiveness of spontaneous attention to form. System, 29(3), 325-340. http://dx.doi.org/10.1016/S0346-251X(01)00022-7 